\title{
Organizational learning
}

\author{
Saeed Tabrizinia ${ }^{a^{*}}$
}

${ }^{a}$ Department of Economy, Management, Accounting ,College of Management, East Azarbaijan Science and Research Branch, Islamic Azad University, Tabriz, Iran

\section{H R O N I C L E}

Article history:

Received January 5, 2016

Received in revised format August 2, 2016

Accepted August 30, 2016

Available online

August 30, 2016

Keywords:

Organizational learning survey

Municipality

Learning skills

\begin{abstract}
A B S T R A C T
This survey aims to evaluate the quality of learning among regular employees and managers who work for Tabriz municipality, District 2 in city of Tabriz, Iran. The study designs a questionnaire consists of 55 questions, which covers five organizational learning survey (OLS) including systematic thinking, personal capabilities, mental models, shared goal and collective learning. Cronbach alpha was calculated as 0.93 , which is well above the desirable level. Using some statistical test, the study has determined that managers maintained higher level of OLS than regular employees. Based on the results of the survey, some suggestions are proposed in order to improve the quality of leaning in the organization.
\end{abstract}

\section{Introduction}

The recent change business environment of the past century has created significant motivation for managers to look for new methods to develop organizations capable of continuous adaptation and to forecast the need for change. Organizational learning, a concept which helps continuous adaptation and improvement, has captured the managers' imagination for seeking to survive the current turbulent operating environment (Noruzy et al., 2013). However, applying organizational learning is not always an easy job. Despite the fact that the literature on this topic has grown quickly over the past few decades, there are few systematic, measurable method available for practical applications of this concept in business organizations (Cook \& Yanow, 1996; March, 1991; Levitt \& March, 1988; Argote, 2012). Seashore Louis and Lee (2016) performed a survey to find out how key elements of school culture were related to teachers' capacity to determine and act on new information on selected teachers from 9 states in the US. They reported that "school cultural components such as academic press, student support, and trust and respect among teachers promote teachers' capacity for organizational learning". They also reported that the role of teacher professional culture in molding the capacity for organizational learning was very crucial. Zappa and Robins (2016) investigated organizational learning through a multilevel network lens. Hahn et al. (2015) reported that several constructs may positively influence on individual * Corresponding author.

E-mail address: saeedtabrizinia@gmail.com (S. Tabrizinia) 
creativity. Leufvén et al. (2015) reported that the dimensions of the learning organization questionnaire was capable of detecting variations across employee's perceptions of the organizational context.

Thakur (2015) investigated the barriers encountered by Indian banks on their journey to become a learning organization and reported that learning environment and employee empowerment were the least focused on dimensions implying that they require attention and need to be investigated to become a learning organization. Goh and Richards (1997) developed an Organizational Learning Survey (OLS) to compute learning capability and discussed the implications of applying such method for intervention and change in building more effective learning organizations. Attewell (1992) developed a method, which emphasizes the role of know-how and organizational learning as potential barriers to adoption of innovations. Li et al. (2014) investigated how entrepreneurs in new ventures utilize their managerial ties to capture opportunity and explored the moderating role of organizational learning. They reported that ties with other organizations maintained a stronger positive effect on opportunity capture than ties with government. In addition, they reported that organizational learning could moderate the relationship between managerial ties and opportunity capture. Zahra (2012) investigated the impact of family ownership on the breadth, depth, and speed of organizational learning and reported that organizational learning, especially its breadth and depth, could positively influence the pace of family firms' entrepreneurship. Cheng et al. (2012) investigated the effects of organizational learning environment factors, including managerial support, job support, and organizational support, on employees' motivation to use a workplace e-learning system and reported that employees' perceptions about the usefulness of the e-learning system maintained important effects on their intention to apply the system in the work setting.

\section{The proposed study}

The primary objective of this paper is to evaluate the quality of learning among regular employees and managers who work for Tabriz municipality, District 2 in city of Tabriz, Iran. The five disciplines of organizational learning are the main component of different studies, which help us develop this type of skill. As many managers have noted, the learning disciplines also provide efficient approaches to deal with the dilemmas. There are two disciplines, which represent approaches of articulating individual and collective aspirations.

Personal Mastery: Personal mastery is the efforts for developing a comprehensive image of our own personal vision, the results we wish to create in our life, alongside a realistic evaluation of the current reality of our life today. This generates an innate tension which could expand our capacity to create better choices and to reach more of the results, which we have chosen.

Shared Vision: The second discipline concentrates on mutual purpose. People with a common purpose may learn to build a sense of commitment in a group by developing shared images of the future they look to generate and the strategies and guiding practices by which they wish to get there.

There are two disciplines associated with the practice of meditative thinking and productive conversation:

Mental Models: This discipline of reflection is concentrated around developing awareness of attitudes of our own and those of others around ourselves. Working with mental models helps us more clearly define present reality.

Team Learning: This discipline is associated with group interaction and through such techniques as dialogue and skillful discussion, small numbers of employees transform their collective thinking, learning to mobilize their energies and actions to reach common objectives and draw forth an intelligence and ability bigger than the sum of individual members' talents. 
Systems Thinking: According to this discipline, people learn to better understand interdependency and change and thereby are capable of dealing more efficiently with the forces that shape the outcomes of their actions.

The proposed study of this paper measures the level of these items among regular employees and managers of a municipality. After preparing a 55-item questionnaire that captured all of the elements found in the literature grouped into the five dimensions discussed earlier, we have refined the questions through a series of focus groups. The sample size is calculated as follows,

$$
n=\frac{N \times z_{\alpha / 2}^{2} \times p \times q}{\varepsilon^{2} \times(N-1)+z_{\alpha / 2}^{2} \times p \times q},
$$

where $N$ is the population size, $p=1-q$ represents the yes/no categories, $z_{\alpha / 2}$ is CDF of normal distribution and finally $\varepsilon$ is the error term. Since we have $p=0.5, z_{\alpha / 2}=1.96$ and $N=210$, the number of sample size is calculated as $n=132$. Fig. 1 demonstrates personal charactersitsics of the participants.

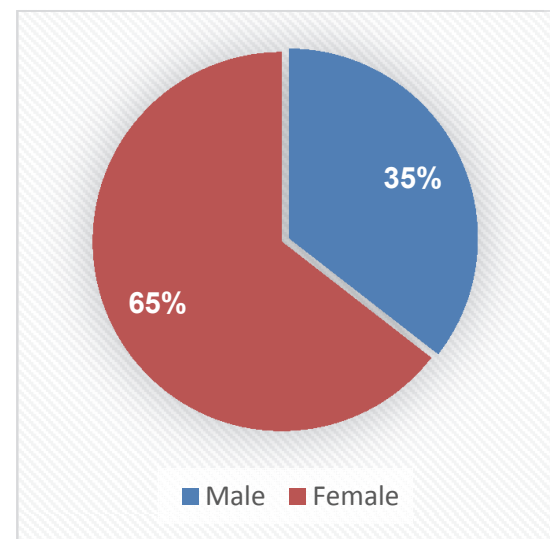

Gender

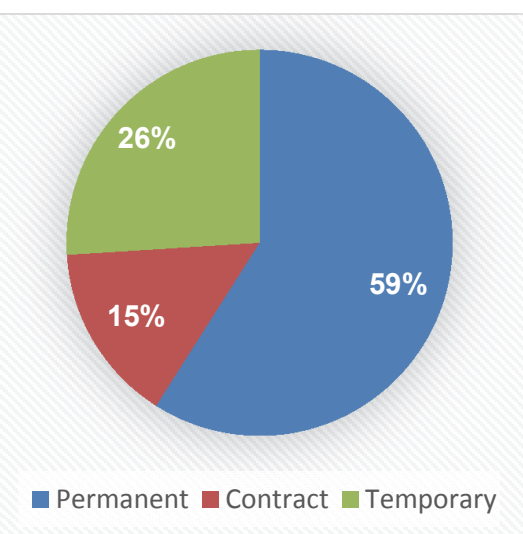

Job status

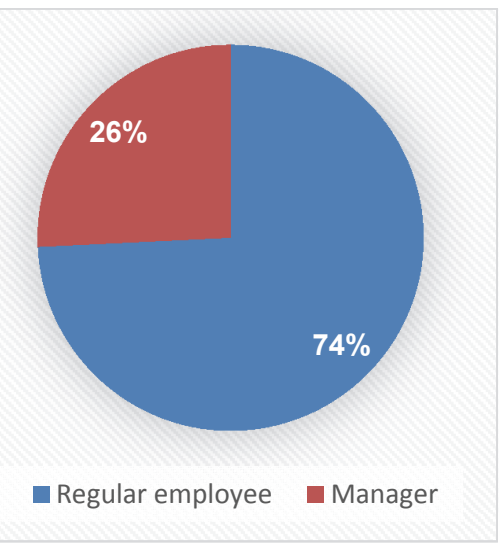

Position

Fig. 1. Personal characteristics of the participants

As we can observe from Fig. 1, more than half of the employee in this organization were female. In addition, more of the employees had permanent job position and only $26 \%$ of them were in temporary contract. Finally, $74 \%$ of the participants in our survey were regular employees and $26 \%$ of them were managers. Kolmogorov Smirnov has indicated that the data were normally distributed. Moreover, the questionnaire of learning organization was used for measuring reliability among 20 employees from the community and its reliability was $93 \%$ obtained using Cronbach alpha, which renders it acceptable for applied cases. In addition, Table 1 presents the summary of some basic statistics on our survey.

Table 1

The results of mean and standard deviation of two groups for five scale test

\begin{tabular}{clcccccc}
\hline \multirow{2}{*}{ Manager } & Statistics & $\begin{array}{c}\text { Systematic } \\
\text { thinking }\end{array}$ & $\begin{array}{c}\text { Personal } \\
\text { capabilities }\end{array}$ & $\begin{array}{c}\text { Mental } \\
\text { models }\end{array}$ & $\begin{array}{c}\text { Shared } \\
\text { goal }\end{array}$ & $\begin{array}{c}\text { Collective } \\
\text { learning }\end{array}$ & $\begin{array}{c}\text { Total mean of } \\
\text { the learning }\end{array}$ \\
& Mean & 16.7 & 15.83 & 16.91 & 15.5 & 16.3 & 82 \\
& Number & 34 & 34 & 34 & 34 & 34 & 34 \\
& Standard & 2.904 & 4.395 & 4.487 & 3.029 & 3.433 & 16.116 \\
\hline \multirow{3}{*}{ Employees } & Mean & 14.29 & 14.72 & 15 & 14.9 & 15.2 & 75.78 \\
& Number & 98 & 98 & 98 & 98 & 98 & 98 \\
& Standard & 4.222 & 4.423 & 4.161 & 4.083 & 4.371 & 19.111 \\
\hline \multirow{3}{*}{ Total } & Mean & 14.37 & 15.92 & 15.27 & 15.83 & 14.79 & 76.18 \\
& Number & 132 & 132 & 132 & 132 & 132 & 132 \\
& Standard & 4.16 & 4.42 & 4.199 & 4.03 & 4.321 & 18.975 \\
\hline
\end{tabular}


Fig. 2 demonstrates the results of mean of measures for the mentioned five scales. As we can observe from the figure, managers tend to have higher levels of organizational learning than regular employees do.

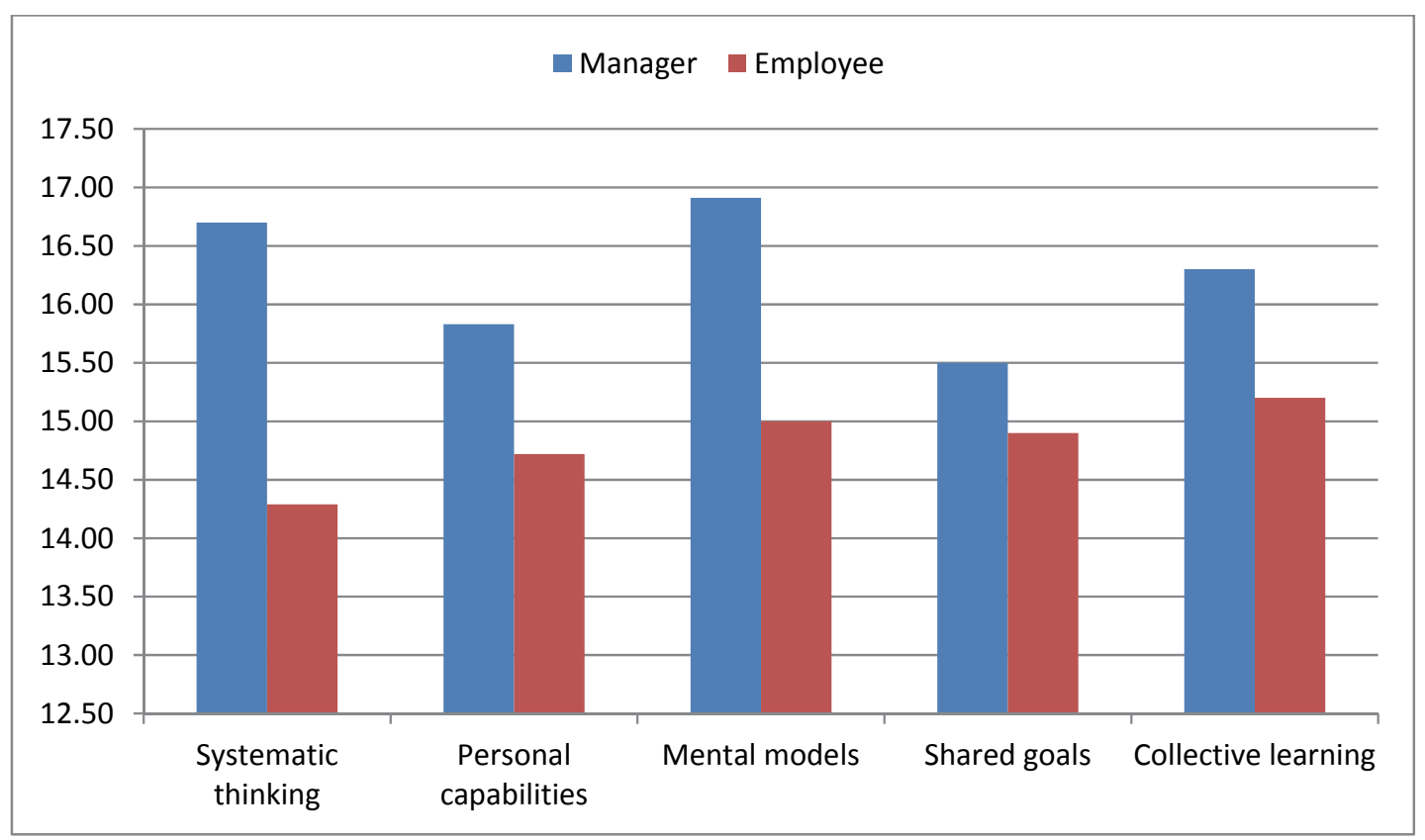

Fig. 2. The summary of mean of scales

In order to understand whether there is any meaningful difference between the mean of two groups, we use t-student test as follows,

$$
\begin{aligned}
& \sigma_{\text {Manager-Regular Employee }}=\sqrt{\frac{\sigma_{\text {Manager }}^{2}}{N_{\text {Manager }}}+\frac{\sigma_{\text {Regular Employee }}^{2}}{N_{\text {Regular Employee }}}}, \\
& z=\frac{\mu_{\text {Manager }}-\mu_{\text {Regular Employee }}}{\sigma_{\text {Manager-Regular Employee }}}
\end{aligned}
$$

where $\sigma_{\text {Manager }}^{2}, \sigma_{\text {Regular Employe }}^{2}$ represent the standard deviation of manager and regular employee, respectively. In addition, $N_{\text {Manager }}$ and $N_{\text {Regular Employee }}$ denote the number of two groups, respectively. Finally, $\mu_{\text {Manager }}$ and $\mu_{\text {Regular Employee }}$ are mean of two groups. Implementation of Eq. (2) and Eq. (3) yields z $=1.93$ with Sig. $=0.000$, which means there is a meaningful difference between OLS of two groups.

\section{Conclusion}

We have presented an empirical investigation to evaluate the quality of learning among regular employees and managers who worked for Tabriz municipality, District 2 in city of Tabriz, Iran. The study designed a questionnaire consists of 55 questions, which covers five organizational learning survey (OLS) including systematic thinking, personal capabilities, mental models, shared goal and collective learning. Using some statistical test, the study has determined that managers maintained higher level of OLS than regular employees. Based on the results of the survey, the following suggestions are proposed in order to improve the quality of leaning in the organization: First, it appears that regular employees' biggest weakness is associated with systematic learning, which is a management discipline that concerns an understanding of a system. In our survey, regular employees need to be justified about organization's objectives and guide them to improve their learning skills. 
Personal capability is the second weakness of regular employees. We believe this sort of skill could be improved through short course programs and they could improve their basic capabilities. Goal setting is another crucial component to any great business strategy and it appears that regular employees had some weakness in this issue. Shared goals creates a culture of accountability and encourages teams to take a public position and motivate one another to accomplish their promises. When someone stops working, the whole team may stay away from the objectives and the key success is to set regular check in points where every regular employee can report on his/her progress.

\section{Acknowledgement}

The authors would like to thank the anonymous reviewers for constructive comments on earlier version of this paper.

\section{References}

Argote, L. (2012). Organizational learning: Creating, retaining and transferring knowledge. Springer Science \& Business Media.

Attewell, P. (1992). Technology diffusion and organizational learning: The case of business computing. Organization Science, 3(1), 1-19.

Cheng, B., Wang, M., Moormann, J., Olaniran, B. A., \& Chen, N. S. (2012). The effects of organizational learning environment factors on e-learning acceptance. Computers \& Education, 58(3), 885-899.

Cook, S. D., \& Yanow, D. (1996). Culture and organizational learning.Organizational learning, 430459.

Goh, S., \& Richards, G. (1997). Benchmarking the learning capability of organizations. European Management Journal, 15(5), 575-583.

Hahn, M. H., Lee, K. C., \& Lee, D. S. (2015). Network structure, organizational learning culture, and employee creativity in system integration companies: the mediating effects of exploitation and exploration. Computers in Human Behavior, 42, 167-175.

Leufvén, M., Vitrakoti, R., Bergström, A., Ashish, K. C., \& Målqvist, M. (2015). Dimensions of Learning Organizations Questionnaire (DLOQ) in a low-resource health care setting in Nepal. Health Research Policy and Systems, 13(1), 1.

Levitt, B., \& March, J. G. (1988). Organizational learning. Annual Review of Sociology, 14, 319-340.

Li, Y., Chen, H., Liu, Y., \& Peng, M. W. (2014). Managerial ties, organizational learning, and opportunity capture: A social capital perspective.Asia Pacific Journal of Management, 31(1), 271291.

March, J. G. (1991). Exploration and exploitation in organizational learning.Organization science, 2(1), 71-87.

Noruzy, A., Dalfard, V. M., Azhdari, B., Nazari-Shirkouhi, S., \& Rezazadeh, A. (2013). Relations between transformational leadership, organizational learning, knowledge management, organizational innovation, and organizational performance: an empirical investigation of manufacturing firms. The International Journal of Advanced Manufacturing Technology,64(5-8), 1073-1085.

Seashore Louis, K., \& Lee, M. (2016). Teachers' capacity for organizational learning: the effects of school culture and context. School Effectiveness and School Improvement, 1-23.

Thakur, N. (2015). Exploring dimensions and demographics in relation to learning organization. The International Journal of Business \& Management,3(3), 334.

Zahra, S. A. (2012). Organizational learning and entrepreneurship in family firms: Exploring the moderating effect of ownership and cohesion. Small business economics, 38(1), 51-65.

Zappa, P., \& Robins, G. (2016). Organizational learning across multi-level networks. Social Networks, 44, 295-306. 


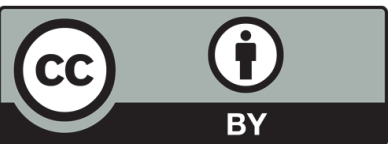

(C) 2016 by the authors; licensee Growing Science, Canada. This is an open access article distributed under the terms and conditions of the Creative Commons Attribution (CC-BY) license (http://creativecommons.org/licenses/by/4.0/). 